\title{
Influence of povidone-iodine on micro- tensile bonding strength to dentin under simulated pulpal pressure
}

\author{
Najlaa M. Alamoudi ${ }^{*}$, Alaa M. Baik², Azza A. El-Housseiny ${ }^{1,3}$, Tariq S. Abu Haimed ${ }^{4}$ and Ahmed S. Bakry ${ }^{5,6}$
}

\begin{abstract}
Background: Previous studies had reported that bond strength deteriorate over time following the dentin surface pretreatment with chlorhexidine. Therefore, further investigations are needed to evaluate the effect of other materials such as povidone iodine.

The purpose of this study was to investigate the effects of $10 \%$ povidone-iodine pretreatment on the resin-dentin micro-tensile bond strength of a single bond adhesive system in permanent teeth over time, and compare it with $2 \%$ chlorhexidine.

Methods: Flat dentin surfaces were prepared in 63 extracted permanent teeth. Teeth were randomly assigned to a 10\% povidone-iodine pretreatment, a $2 \%$ chlorhexidine pretreatment, or a control group. Composite resin blocks were built up over treated surfaces under pulp pressure simulation. The prepared specimens were assigned to three storage time, $24 \mathrm{~h}$, 1 week, and 2 months. Samples were vertically sectioned to obtain specimens of 0.7 to $1.2 \mathrm{~mm}^{2}$ cross-sectional area.

Results: No significant reduction of bond strength of povidone iodine group was found among the three storage times $(p=0.477)$. A significant reduction of bond strength for both chlorhexidine and control groups was found in the three storage times $(p<0.001)$.

Conclusion: Povidone iodine pretreatment of etched dentin was effective in reducing the loss of bond strength over time, while the chlorhexidine pretreatment and negative control showed significant deterioration in micro-tensile bond strength over time in permanent teeth.
\end{abstract}

Keywords: Matrix metalloproteinase, Micro-tensile bond strength, Povidone-iodine, Chlorhexidine

\section{Background}

A current area of interest in adhesive dentistry is the durability of resin restorations [1]. The generation of resin-dentin bonds entails various challenges, including the preservation of structural integrity and strength. The bonds between resin and dentin using dentin adhesive systems can become damaged over time [2]. Aged composite resin bonded to dentin reportedly exhibited hydrolytic degeneration of collagen [1] without any bacterial enzymes [2].

Matrix metalloproteinases (MMPs) are part of the composition of dentin structure [3]. They are a group of

\footnotetext{
*Correspondence: nalamoudi@kau.edu.sa; nalamoudi2011@gmail.com

${ }^{1}$ Pediatric Dentistry Department, Faculty of Dentistry, King Abdulaziz

University, P.O. Box 80209, Jeddah 21589, Saudi Arabia

Full list of author information is available at the end of the article
}

proteases that can destroy the organic matrix of etched dentin [4]. All MMP family members are secreted as inactive proenzymes (Pro-MMPs). Pro-MMPs can be activated by proteases, other members of the MMP family, acids, reactive oxygen, and denaturants [2]. These Pro-MMPs need calcium ion $\left(\mathrm{Ca}^{2+}\right)$ for their activation. Following bacterial demineralization, $\mathrm{Ca}^{2+}$ ions are released and act as a cofactor for the Pro-MMPs activation. These MMPs lead to dentin destruction. Similarly, following acid etching demineralization, MMPs are released and activated [2].

Establishing adhesion to mineralized tissue is based on the reaction of biologic apatite with acids. Etching dentin with $37 \%$ phosphoric acid lead to hydroxyapatite crystals dissolution, demineralization of the surface of the dentin matrix, exposure of the underlying collagen

(c) The Author(s). 2018 Open Access This article is distributed under the terms of the Creative Commons Attribution 4.0 International License (http://creativecommons.org/licenses/by/4.0/), which permits unrestricted use, distribution, and 
and creates porosities within that collagen matrix. A demineralized microporous area composed of organic dentin material mainly collagen fibrils is formed. This allows solvated monomers to infiltrate around and into spaces of collagen fibrils to obtain retention for resincomposite materials. However, acid etchings release the $\mathrm{Ca}^{2+}$ ions and activate MMPs. These MMPs lead to collagen destruction leading to enzymatic degradation of hybrid layer and subsequently endanger resin-dentin bonding longevity [4]. In order to prevent enzymatic degradation, inhibitors of MMP activity have been applied during adhesive application [5]. One such enzymatic inhibitor is chlorhexidine [2].

Povidone-iodine (PVP-I) was introduced as an antiseptic agent in the 1950s, and is as effective as iodine alone against a broad spectrum of disease-causing microorganisms [6, 7]. It is an organic water-soluble complex that contains molecular iodine and the solubilizing agent polyvinyl pyrrolidone. It is less irritating to the skin than iodine, and unlike iodine it does not require iodides or alcohol to dissolve. Moreover, PVP-I stains are water-soluble.

It has been claimed that PVP-I can induce an endogenous proteinase inhibitor capable of blocking enzymatic activity $[8,9]$. Reductions in the collagenolytic activity of MMP- 9 by $83 \%$ and MMP- 2 by $88 \%$ were reported after $24 \mathrm{~h}$ of PVP-I application on nitrogen and sulfur mustard-induced skin lesions. When skin was analyzed 48 and $72 \mathrm{~h}$ after exposure, a similar trend of PVP-I-induced reduction in the two types of collagenase activity was found [8].

The hydrolytic and enzymatic stability of dental adhesives in the oral environment is a concern because the oral environment can severely compromise the durability of resin-dentin bonds. A literature review was performed prior to the current study, to investigate the effects of using chlorhexidine as a MMP inhibitor on dentin substrates, and the influence of chlorhexidine application on the preservation of dentin bond durability. Previous studies have reported that bond strength deteriorated over time following dentin surface pretreatment with chlorhexidine $[10,11]$. This suggested that further investigations were needed to evaluate the effects of other materials such as PVP-I on the durability of dentin micro-tensile bond strength (MTBS).

The aim of this study was to evaluate the effects of $10 \%$ PVP-I pretreatment on dentin MTBS, and compare it with $2 \%$ chlorhexidine pretreatment and no pretreatment in permanent teeth over a period of 2 months.

\section{Methods}

\section{Specimen preparation}

The protocol of this study was approved by the ethics committee, King Abdulaziz University, Jeddah, Saudi Arabia. This is a randomized experimental in vitro study.
Collecting bottles containing 0.5\% Chloramine $\mathrm{T}$ were distributed to different private and governmental clinics in Jeddah to collect the freshly extracted sound teeth on it. Contact information was given to the dental assistant in charge for each clinic to contact us as soon as the teeth are extracted. Informed consent form was obtained and signed from patients to use their teeth for this research. Sixty-three extracted intact, non-carious, non-restored human permanent third molars were collected. The molars were mounted in 2-cm-diameter cylindrical customized molds using chemically cured acrylic resin (Major Prodotti Dentari Spa, Moncalieri, Italy). The roots were embedded $3 \mathrm{~mm}$ below the cementoenamel junction with the long axis of each tooth parallel to the walls of the mold. Each tooth was transversally cut in two steps using a slow speed diamond saw (TECHCUT $4^{\mathrm{rm}}$, Allied High Tech Products, Inc., USA) under copious water irrigation. The first cut was perpendicular to the long axis of each tooth at the coronal part of the crown, to remove the occlusal surfaces of the crowns leaving flat mid-coronal dentin. The subsequent cut was at a level approximately $1 \mathrm{~mm}$ below the cementoenamel junction and parallel to the flat dentin surface, to remove the root portion and expose the pulp chamber, from which the pulp tissue was carefully removed using tweezers.

\section{Simulating pulpal pressure}

In an attempt to simulate intra-oral conditions, simulated pulp pressure was employed (Fig. 1). All restorative procedures including dentin adhesive bonding were performed under simulated dentinal hydrostatic pressure. Each segment was attached to a petri dish from the pulpal area and penetrated by a 21-gauge stainless steel needle. A flexible tube was connected and sealed to the stainless steel needle and to the back of the petri dish using cyanoacrylate adhesive (Zapit; DVA, Corona, CA, USA). The other end of this tube was sealed to a plastic syringe to maintain an airtight seal. The plastic syringe and the flexible tube were then filled with distilled water. The 1-mm root of the crown segment was bonded and sealed to the inner side of the petri dish using a cyanoacrylate adhesive. The intra pulpal pressure assembly was fixed to a burette stand. To generate an intra-pulpal pressure of $15 \mathrm{~cm} \mathrm{H}_{2} \mathrm{O}$, the level of distilled water in the $10-\mathrm{mL}$ plastic syringe was adjusted $15 \mathrm{~cm}$ vertically above the flat dentin surface of the tested tooth.

\section{Acid etching and pretreatment}

The teeth were randomly assigned to three groups according to the pretreatment solution. Each group had 21 teeth. The teeth were etched with 35\% phosphoric acid gel (Scotchbond Universal Etchant, 3 M ESPE, St Paul, $\mathrm{MN}$, USA) for $15 \mathrm{~s}$ and rinsed with water for $10 \mathrm{~s}$. They were then placed in 10\% PVP-I solution for $60 \mathrm{~s}$ in group 


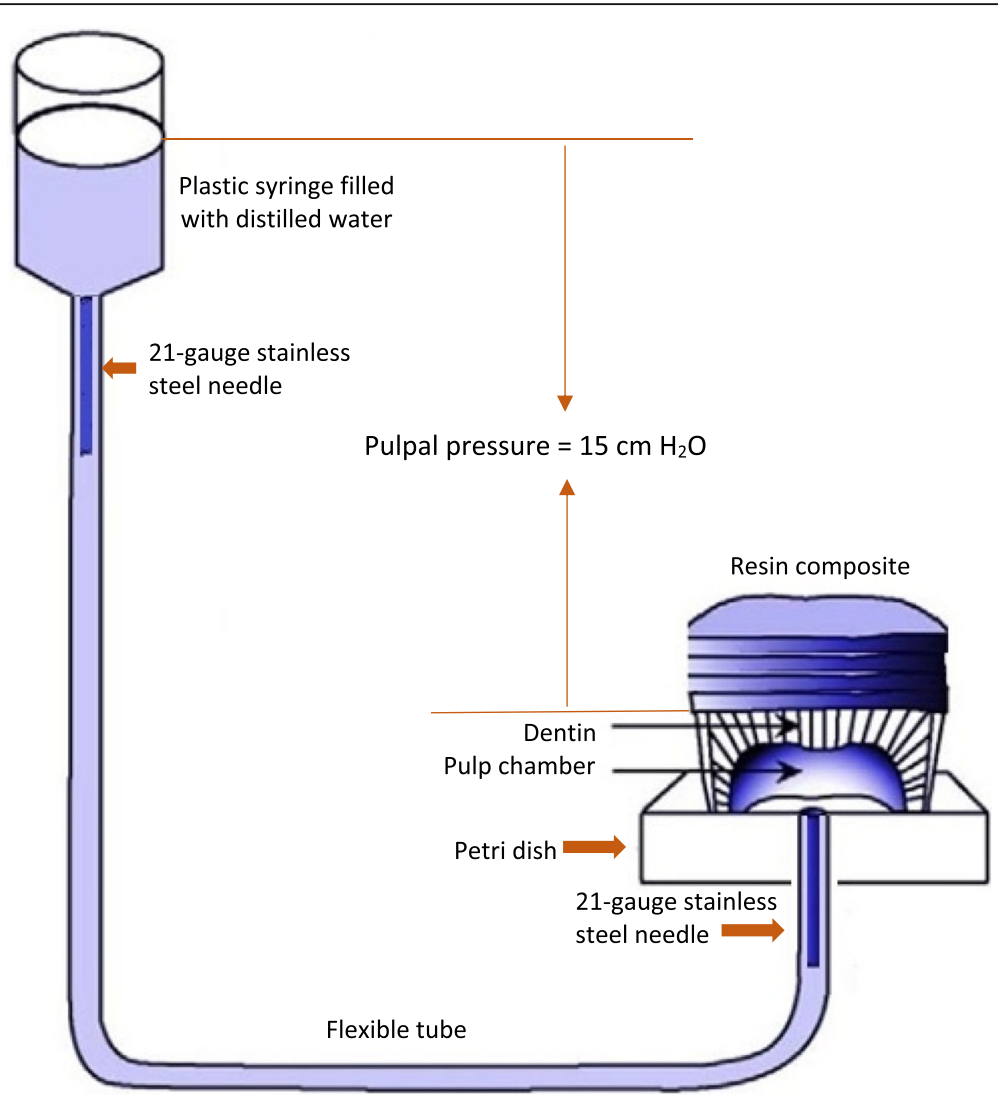

Fig. 1 Illustration depicting the intra-pulpal pressure simulation apparatus used in this study

1, $2 \%$ chlorhexidine solution for $60 \mathrm{~s}$ in group 2, and in water in the control group (no pretreatment). The dentin surface was dried for $10 \mathrm{~s}$ with an oil-and-water-free air source with pressure to remove excess water and pretreatment solutions. Two coats of the single bond (Adper Single Bond 2, 3 M ESPE, St Paul, MN, USA) were applied to the entire flat occlusal surface of the dentin with $5 \mathrm{~s}$ of air-drying after each application, before being cured for $10 \mathrm{~s}$ with a quartz-tungsten-halogen light-curing unit (Curing Light 2500, $3 \mathrm{M}$ EPSE) delivering $600 \mathrm{~mW} / \mathrm{cm}^{2}$. A composite resin (Filtek Z250, 3 M ESPE, St Paul, MN, USA) crown of $4 \mathrm{~mm}$ in height was incrementally applied to the bonded dentin surface in 1-mm increments. A celluloid strip was used to separate the composite and the light curer tip. Each composite increment was light-cured for $30 \mathrm{~s}$.

The prepared specimens were randomly assigned to three storage time subgroups containing 7 teeth each: $24 \mathrm{~h}, 1$ week, and 2 months. Samples were stored in distilled water and placed in an incubator at $37^{\circ} \mathrm{C}$, and the distilled water was changed periodically.

\section{Sample preparation for MTBS}

At each designated time-point ( $24 \mathrm{~h}, 1$ week, 2 months), the teeth in the relevant subgroups were vertically sectioned across the bonded interface (in the occluso-gingival direction) into multiple serial sections using a low speed saw (TECHCUT $4^{\mathrm{Tx}}$, Allied High Tech Products, Inc., USA) at a cutting speed of $200 \mathrm{rpm}$. Each crown segment was sectioned into two or three slabs, then each slab was rotated 90 degrees in the same plane and another two or three sections were made perpendicular to the slabs, resulted in four to six sticks. The cross-sectional areas of the selected specimens were measured using a digital caliper to the nearest $0.01 \mathrm{~mm}$ for subsequent bond strength evaluation.

\section{MTBS}

To test MTBS, the end of each stick was fixed to the flat stainless steel microgrip of a universal testing machine (Micro-tensile Tester; Bisco, Schaumburg, IL) using cyanoacrylate glue (Zapit; DVA, Corona, CA, USA). The specimens were tension-stressed until failure occurred, using a simplified universal testing machine at a crosshead speed of $1 \mathrm{~mm} /$ minute. MTBS was calculated as the maximum load at failure divided by the cross-sectional area of each stick, and was recorded in MPa. The mean MTBS for each group was calculated and the three groups were compared.

\section{Failure mode analysis}

The fractured specimens were kept in distilled water for $24 \mathrm{~h}$. All debonded surfaces (dentin and resin) were 


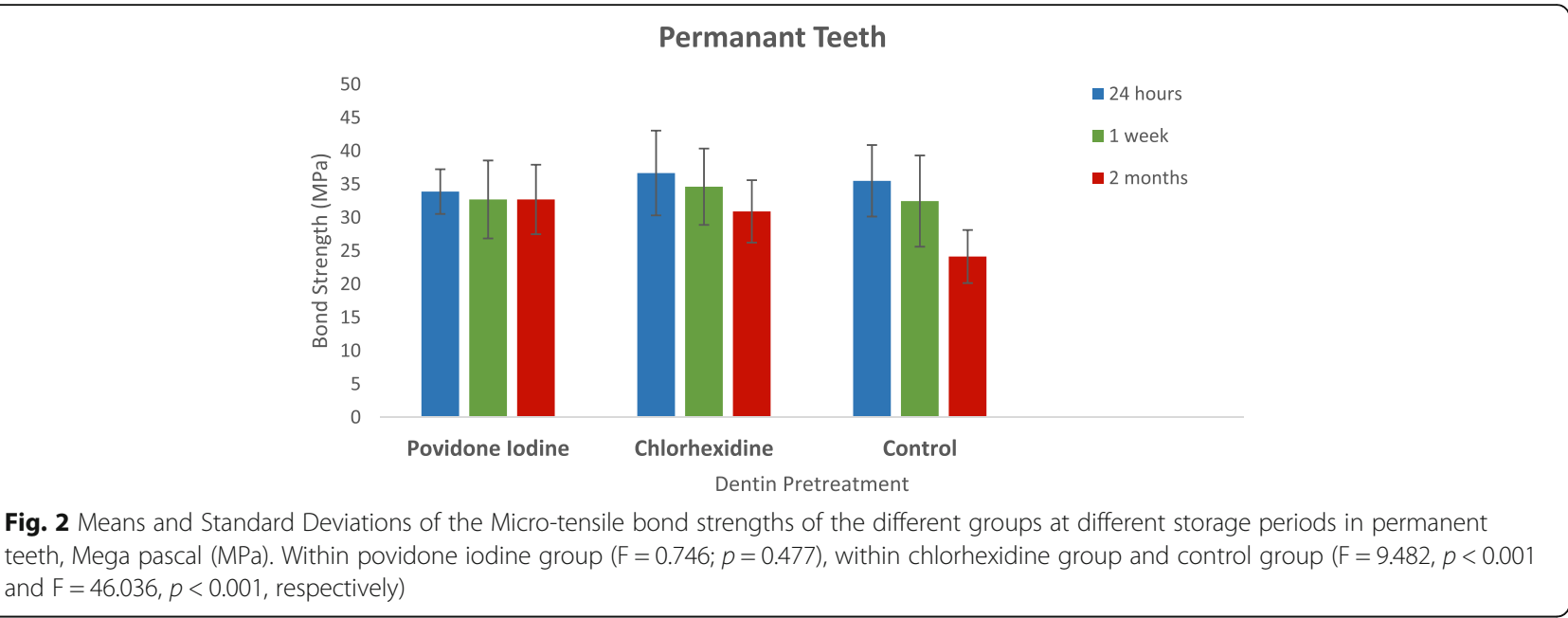

evaluated under a stereomicroscope (Meiji Techno Co. Ltd., Tokyo, Japan) at 50x magnification to assess the mode of failure. The failure modes of the fractured specimens were categorized as adhesive failure when the fracture occurred between adhesive and dentin, cohesive failure in dentin when dentin covered the two fractured parts of the specimen, cohesive failure in resin material when the two parts of the specimens were fully covered with composite resin, or mixed failure when there were two or more of the types of fractures described above.

\section{Statistical analysis}

The data were tested for normality using the Shapiro-Wilks test. One-way analysis of variance was conducted to assess the pretreatment effect on resin-dentin bond strength at each storage time-point, and to evaluate the effect of storage time on the resin-dentin bond strength within each pretreatment group (i.e., assuming the samples were independent). The post-hoc Bonferroni test was used for multiple pairwise comparisons to identify any significant differences between groups. All tests employed a 0.05 level of statistical significance.

\section{Results}

A total of 376 specimens were subjected to MTBS testing and fracture mode analysis. There were 38 cohesive failures among the 376 sticks. These cohesive failures were either in dentin or in resin material, which does not represent the actual resin-dentin bond strength. Therefore, it was not included in the statistical analysis [12]. The remaining 338 specimens were included in the statistical analysis. The power of the sample size at an alpha value of 0.05 was 1.00 . Figure 2 present the mean and standard deviation of each group.

One-way analysis of variance revealed that there was no significant reduction in resin-dentin bond strength in the PVP-I surface pretreatment group at any of the three storage time-points $(\mathrm{F}=0.746 ; p=0.477)$. Conversely, there were significant reduction in resin-dentin bond strength in the chlorhexidine surface pretreatment group and the control group (no pretreatment) at the three storage time-points $(\mathrm{F}=9.482, p<0.001$ and $\mathrm{F}=46.036$, $p<0.001$, respectively). The post-hoc Bonferroni test indicated that there was no significant loss of resin-dentin bond strength between $24 \mathrm{~h}$ and 1 week in the chlorhexidine group. In the control group, the mean bond strength at 1 week was significantly lower than that at $24 \mathrm{~h}$. Additionally, in both the chlorhexidine group and the control group the mean bond strength at 2 months was significantly lower than those at 1 week and at $24 \mathrm{~h}$. Detailed results from the post-hoc Bonferroni test are shown in Tables 1 and 2.

The analyses revealed significant associations between storage time and failure mode within the PVP-I group and the chlorhexidine group. Table 3 shows the associations between storage time and failure mode within each study group.

\section{Discussion}

In the present study, only freshly extracted, non-carious, permanent molars were utilized in an attempt to standardize the dentin substrates used. Intact resin-bonded teeth were stored in distilled water under simulated pulpal pressure. The water exposure of intact resin-bonded teeth may resemble a more realistic clinical situation in terms of hydrolytic

Table 1 Post-hoc test for resin-dentin micro-tensile bond strength in the chlorhexidine group

\begin{tabular}{lll}
\hline Post-hoc $^{\mathrm{a}}$ & & $p$ value \\
\hline $24 \mathrm{~h}$ & 1 week & 0.386 \\
1 week & 2 months & $0.021^{*}$ \\
2 months & $24 \mathrm{~h}$ & $<0.001^{*}$ \\
\hline
\end{tabular}

aBonferroni test

"Statistically significant at $p<0.05$ 
Table 2 Post-hoc test for resin-dentin micro-tensile bond strength in the control group

\begin{tabular}{lll}
\hline Post-hoc $^{\mathrm{a}}$ & $p$ value \\
\hline $24 \mathrm{~h}$ & 1 week & $0.049^{*}$ \\
1 week & 2 months & $<0.001^{*}$ \\
2 months & $24 \mathrm{~h}$ & $<0.001^{*}$
\end{tabular}

${ }^{a}$ Bonferroni Test

*Statistically significant at $p<0.05$

degradation than smaller resin-dentin specimens directly exposed to water. Simulated pulpal pressure was used in this in vitro study in an attempt to achieve reliable results that were relevant to real clinical conditions. Simulated pulp pressures ranging from 30 to $37 \mathrm{~cm} \mathrm{H}_{2} \mathrm{O}$ have been used in many studies investigating the influence of intra-pulpal pressure on the bonding effectiveness of adhesives to dentin [13-15]. In the current study, a lower intra-pulpal pressure was utilized because the intra-pulpal pressure in normal pulp is not as high as previously established [16]. Previous in vivo studies have reported that values of approximately $15 \mathrm{~cm} \mathrm{H}_{2} \mathrm{O}$ should be used to simulate normal pulp pressure $[16,17]$.

In the current study, conventional two step etch-andrinse adhesive was used (Single Bond, $3 \mathrm{M}$ ESPE, St.
Paul, MN, USA) which has a pH of 3.6 [18]. Previous studies have suggested that low $\mathrm{pH}$ (4.5) acids are capable of activating MMPs $[4,19]$. Therefore, it was hypothesized that this adhesive would be capable of activating dentin proteolytic enzymes derived from the underlying partially-demineralized dentin [20].

In the current study, we used 10\% PVP-I and $2 \%$ chlorhexidine as therapeutic primers of etched dentin. The PVP-I and chlorhexidine were applied to etched dentin before bonding, and the excess was air-dried without rinsing. The technique used in this experiment was a wet bonding technique. PVP-I and chlorhexidine digluconate are soluble in water. The differences in the binding performances of PVP-I and chlorhexidine to collagen and hydroxyl apatite are unknown.

Chlorhexidine has a high affinity to dentin. It can bind electrostatically to the phosphate groups of dentin and to carboxyl groups of collagen fibers. However, chlorhexidine composed of a large water-soluble molecule that might be leaded out of dentin over time [21]. Moreover, the binding mechanism between the PVP-I and the dentinal structure is not clear. However, the application of a miscible (capable of mixing in any ratio without separation of two phases) solution to water-saturated dentin

Table 3 Associations between storage time and failure mode in permanent teeth in each group

\begin{tabular}{|c|c|c|c|c|c|c|}
\hline \multirow{2}{*}{$\begin{array}{l}\text { Dentin surface } \\
\text { pretreatment }\end{array}$} & \multirow[t]{2}{*}{ Type of failure } & \multicolumn{3}{|c|}{ Storage time } & \multirow[t]{2}{*}{ Total (\%) } & \multirow[t]{2}{*}{$\overline{p \text { value }}{ }^{+}$} \\
\hline & & 24 h (\%) & 1 week (\%) & 2 months (\%) & & \\
\hline \multirow[t]{5}{*}{ Povidone-iodine } & Adhesive failure & $38(88.4)$ & $32(82.1)$ & $26(60.5)$ & $96(76.8)$ & $0.007^{*}$ \\
\hline & Cohesive in dentin & $0(0)$ & $0(0)$ & $4(9.3)$ & $4(3.2)$ & \\
\hline & Cohesive in composite & $0(0)$ & $4(10.3)$ & $5(11.6)$ & $9(7.2)$ & \\
\hline & Mixed failure & $5(11.6)$ & $3(7.7)$ & $8(18.6)$ & $16(12.8)$ & \\
\hline & Total & $43(100)$ & $39(100)$ & $43(100)$ & $125(100)$ & \\
\hline \multirow[t]{5}{*}{ Chlorhexidine } & Adhesive failure & $36(90.0)$ & $33(84.6)$ & $24(61.5)$ & $93(78.8)$ & $0.013^{*}$ \\
\hline & Cohesive in dentin & $0(0)$ & $1(2.6)$ & $1(2.6)$ & $2(1.7)$ & \\
\hline & Cohesive in composite & $2(5.0)$ & $0(0)$ & $5(12.8)$ & $7(5.9)$ & \\
\hline & Mixed failure & $2(5.0)$ & $5(12.8)$ & $9(23.1)$ & $16(13.6)$ & \\
\hline & Total & $40(100)$ & $39(100)$ & $39(100)$ & $118(100)$ & \\
\hline \multirow[t]{5}{*}{ Control } & Adhesive failure & $37(84.1)$ & $36(81.8)$ & $30(66.7)$ & $103(77.4)$ & 0.053 \\
\hline & Cohesive in dentin & $3(6.8)$ & $1(2.3)$ & $0(0)$ & $4(3.0)$ & \\
\hline & Cohesive in composite & $1(2.3)$ & $3(6.8)$ & $8(17.8)$ & $12(9.0)$ & \\
\hline & Mixed failure & $3(6.8)$ & $4(9.1)$ & $7(15.6)$ & $14(10.5)$ & \\
\hline & Total & $44(100)$ & $44(100)$ & $45(100)$ & $133(100)$ & \\
\hline \multirow[t]{5}{*}{ Total } & Adhesive failure & $111(87.4)$ & $101(82.8)$ & $80(63.0)$ & $292(77.7)$ & $<0.001^{*}$ \\
\hline & Cohesive in dentin & $3(2.4)$ & $2(1.6)$ & $5(3.9)$ & $10(2.7)$ & \\
\hline & Cohesive in composite & $3(2.4)$ & $7(5.7)$ & $18(14.2)$ & $28(7.4)$ & \\
\hline & Mixed failure & $10(7.9)$ & $12(9.8)$ & $24(18.9)$ & $46(12.2)$ & \\
\hline & Total & $127(100)$ & $122(100)$ & $127(100)$ & $376(100)$ & \\
\hline
\end{tabular}


after etching and rinsing should maximize chlorhexidine concentration within the hybrid layer [21]. Without rinsing, excess PVP-I and chlorhexidine may be incorporated into the primer, and released slowly over time [21]. Previous studies have reported that PVP-I has the capacity to be slowly released over time [22-24].

In the present study, the PVP-I group showed no significant reduction in dentin bond strength at the $24 \mathrm{~h}, 1$ week, or 2 months time-points. In contrast, the chlorhexidine and control groups showed significant reductions in dentin bond strength at 1 week and at 2 months. The differences in mean dentin bond strength in the chlorhexidine and control groups between $24 \mathrm{~h}$ and 2 months were approximately $6 \mathrm{MPa}$ and $11 \mathrm{MPa}$, respectively, while the corresponding reduction in the PVP-I group was only $\sim 1 \mathrm{MPa}$. This finding may be explained by the superior water solubility of PVP-I compared to chlorhexidine, and the capacity of PVP-I to slowly release iodine over time [25], which ensures the establishment of a nontoxic, optimal concentration of iodine $[26,27]$. This may have resulted in better penetration of PVP-I and inhibition of the MMPs within dentin.

In accordance with the results of previous studies [28-32], in the current study chlorhexidine application after acid etching had no effect on immediate or 1-week resin-dentin bond strength. This is concordant with previous in vitro [33] and in vivo [34] studies using an etch-and-rinse adhesive. Carrilho et al. [33] [34] found that treating etched dentin surfaces of permanent teeth with $2 \%$ chlorhexidine did not affect the in vitro or in vivo MTBS of specimens tested at $24 \mathrm{~h}$. Furthermore, a meta-analysis of the effects of $2 \%$ chlorhexidine vs. control at baseline (immediate bond strength) revealed no statistically significant difference between groups [35].

In the current study, all the teeth were subjected to pulpal pressure simulation. Campos et al. [36] studied the effects of $0.2 \%$ and $2.0 \%$ chlorhexidine on dentin bonding durability. Two-step etch-and-rinse (Single-Bond) and all-in-one self-etch adhesive (Clearfil Tri $\mathrm{S}$ Bond) were used, and all the teeth were subjected to $30 \mathrm{~cm} \mathrm{H}_{2} \mathrm{O}$ pulpal pressure and thermo-mechanical stressing. They reported that MTBS was significantly higher in the groups treated with two-step etch-and-rinse adhesive associated with $0.2 \%$ and $2.0 \%$ chlorhexidine than it was in the control group without chlorhexidine. Additionally, there were no significant differences in MTBS between the group treated with Clearfil Tri S Bond, the control group, and the group treated with $0.2 \%$ chlorhexidine after 6 months. Chlorhexidine was reportedly able to reduce the loss of bond strength of single bond adhesive, but not all-in-one self-etch adhesive, after storage for 6 months under simulated pulpal pressure. Those results are concordant with the results of the current study.

The current study had some limitations. The etch-andrinse system was used in the current study to bond to sound dentin, and thus it may be that the hybrid layer in the current study was infiltrated by the water [37] utilized to exert the pulpal pressure on the dentin surface. However, the presence of an enamel rim sealing the boundaries of the specimens prevented the leaching out of any plasticized adhesive monomer into the storage media [36], and thus diminished the effect of pulpal pressure on the observed bond strength. Additionally, being an in vitro study the results do not directly reflect the clinical conditions of actual teeth, however, simulated pulp pressure was used during bonding and ageing to simulate in vivo conditions. Further clinical studies are needed to confirm the results of the current study.

To the best of our knowledge, this is the first report of data on the effects of PVP-I as a MMP inhibitor on the preservation of dentin bond durability. The results showed that PVP-I, an experimental therapeutic primer, also prevented bond strength deterioration over 2 months of aging. Further studies are needed to explore the reasons behind the preservation of the bond strength. Additionally, long-term studies are needed to evaluate the effects of PVP-I on bond strength. Further studies are also needed to study the inhibitory effects of PVP-I on MMPs directly.

\section{Conclusion}

Povidone iodine pretreatment of etched dentin was effective in reducing the loss of bond strength over time, while the chlorhexidine pretreatment and negative control showed significant deterioration in micro-tensile bond strength over time in permanent teeth.

\section{Abbreviations}

MMPs: Matrix metalloproteinases; MTBS: Micro-tensile bond strength; PVP-I: Povidone-iodine

\section{Acknowledgments}

The authors acknowledge with thanks the Deanship of Scientific Research DSR for their technical and financial support and Dr. Faisal Dardeer for his assistance with sample preparation. We would also like to thank Editage (https://www.editage.com) for English language editing.

\section{Funding}

This research received a grant from the Deanship of Scientific Research (DSR) with grand G-41-165-38.

\section{Availability of data and materials}

All the available data are presented in the tables and figures in the manuscript. However, we will gladly consider sharing the data upon justifiable request from editors, reviewer or researchers.

\section{Authors' contributions}

NMA made substantial contributions to the conception and design of the study and the development of the survey instrument, analyzed and

interpreted the data, and was a major contributor in writing the manuscript, AMB Literature search, study selection, eligibility criteria, data extraction, AAE Analyzing data and manuscript writing, TSA participated in the design, and critically reviewed the manuscript and reviewed data extraction and manuscript writing, ASB participated in the design, and critically reviewed the manuscript and reviewed data extraction and manuscript writing. All authors read and approved the final manuscript. 


\section{Ethics approval and consent to participate}

The research was performed in accordance of King Abdulaziz University, Deanship of Scientific Research, reviewed and approved with the Proposal number 012-16.

\section{Consent for publication}

Not applicable.

\section{Competing interests}

The authors declare that they have no competing interest.

\section{Publisher's Note}

Springer Nature remains neutral with regard to jurisdictional claims in published maps and institutional affiliations.

\section{Author details}

${ }^{1}$ Pediatric Dentistry Department, Faculty of Dentistry, King Abdulaziz University, P.O. Box 80209, Jeddah 21589, Saudi Arabia. ${ }^{2}$ Pediatric Dentistry Department, King Abdulaziz University Dental Hospital, Jeddah, Saudi Arabia. ${ }^{3}$ Pediatric Dentistry Department, Faculty of Dentistry, Alexandria University, Alexandria, Egypt. ${ }^{4}$ Biomaterial Department, Faculty of Dentistry, King Abdulaziz University, Jeddah, Saudi Arabia. ${ }^{5}$ Operative Dentistry Department, Faculty of Dentistry, King Abdulaziz University, Jeddah, Saudi Arabia. ${ }^{6}$ Conservative Dentistry Department, Faculty of Dentistry, Alexandria University, Alexandria, Egypt.

Received: 14 February 2018 Accepted: 18 October 2018

Published online: 29 October 2018

\section{References}

1. Hashimoto M, Ohno H, Kaga M, Endo K, Sano H, Oguchi H. In vivo degradation of resin-dentin bonds in humans over 1 to 3 years. J Dent Res. 2000;79:1385-91.

2. Pashley DH, Tay FR, Yiu C, Hashimoto M, Breschi L, Carvalho RM, et al. Collagen degradation by host-derived enzymes during aging. J Dent Res. 2004;83:216-21.

3. Palosaari H, Pennington CJ, Larmas M, Edwards DR, Tjäderhane L, Salo T. Expression profile of matrix metalloproteinases (MMPs) and tissue inhibitors of MMPs in mature human odontoblasts and pulp tissue. Eur J Oral Sci. 2003;111:117-27.

4. Tjäderhane L, Larjava H, Sorsa T, Uitto VJ, Larmas M, Salo T. The activation and function of host matrix metalloproteinases in dentin matrix breakdown in caries lesions. J Dent Res. 1998;77:1622-9.

5. Breschi L, Mazzoni A, Nato F, Carrilho M, Visintini E, Tjäderhane L, et al. Chlorhexidine stabilizes the adhesive interface: a 2-year in vitro study. Dent Mater. 2010;26:320-5.

6. Siggia S. The chemistry of polyvinylpyrrolidone-iodine. J Am Pharm Assoc Am Pharm Assoc. 1957:46:201-4.

7. Shelanski HA, Shelanski MV. PVP-iodine: history, toxicity and therapeutic uses. J Int Coll Surg. 1956:25:727-34.

8. Wormser U, Brodsky B, Reich R. Topical treatment with povidone iodine reduces nitrogen mustard-induced skin collagenolytic activity. Arch Toxicol. 2002;76:119-21.

9. Shi L, Ermis R, Kiedaisch B, Carson D. The effect of various wound dressings on the activity of debriding enzymes. Adv Skin Wound Care. 2010;23:456-62.

10. Sadek FT, Braga RR, Muench A, Liu Y, Pashley DH, Tay FR. Ethanol wet-bonding challenges current anti-degradation strategy. J Dent Res. 2010;89:1499-504.

11. Pashley DH, Tay FR, Imazato S. How to increase the durability of resindentin bonds. Compend Contin Educ Dent. 2011:32:60-4.

12. De Munck J, Van Meerbeek B, Yoshida Y, Inoue S, Vargas M, Suzuki K, et al. Four-year water degradation of total-etch adhesives bonded to dentin. J Dent Res. 2003:82:136-40.

13. Gernhardt CR, Schaller HG, Kielbassa AM. The influence of human plasma used for dentin perfusion on tensile bond strength of different light-curing materials. Am J Dent. 2005;18:318-22.

14. Moll K, Haller B. Effect of intrinsic and extrinsic moisture on bond strength to dentine. J Oral Rehabil. 2000;27:150-65.

15. Moll K, Park HJ, Haller B. Effect of simulated pulpal pressure on dentin bond strength of self-etching bonding systems. Am J Dent. 2005;18:335-9.

16. Ciucchi B, Bouillaguet S, Holz J, Pashley D. Dentinal fluid dynamics in human teeth, in vivo. J Endod. 1995;21:191-4.
17. Vongsavan N, Matthews B. Fluid flow through cat dentine in vivo. Arch Oral Biol. 1992;37:175-85.

18. Abu Nawareg M, Elkassas D, Zidan A, Abuelenain D, Abu Haimed T, Hassan $\mathrm{AH}$, et al. Is chlorhexidine-methacrylate as effective as chlorhexidine digluconate in preserving resin dentin interfaces? J Dent. 2016;45:7-13.

19. Vuotila T, Ylikontiola L, Sorsa T, Luoto H, Hanemaaijer R, Salo T, et al. The relationship between MMPs and $\mathrm{pH}$ in whole saliva of radiated head and neck cancer patients. J Oral Pathol Med. 2002;31:329-38.

20. Perote LC, Kamozaki MB, Gutierrez NC, Tay FR, Pucci CR. Effect of matrix metalloproteinase-inhibiting solutions and aging methods on dentin bond strength. J Adhes Dent. 2015:17:347-52.

21. Carrilho MR, Carvalho RM, Sousa EN, Nicolau J, Breschi L, Mazzoni A, et al. Substantivity of chlorhexidine to human dentin. Dent Mater. 2010;26:779-85.

22. Durani $P$, Leaper D. Povidone-iodine: use in hand disinfection, skin preparation and antiseptic irrigation. Int Wound J. 2008:5:376-87.

23. Stadelmann WK, Digenis AG, Tobin GR. Impediments to wound healing. Am J Surg. 1998:176:39S-47S.

24. Quirynen M, Teughels W, De Soete M, van Steenberghe D. Topical antiseptics and antibiotics in the initial therapy of chronic adult periodontitis: microbiological aspects. Periodontol 2000. 2002;28:72-90.

25. Thomas GW, Rael LT, Bar-Or R, Shimonkevitz R, Mains CW, Slone DS, et al. Mechanisms of delayed wound healing by commonly used antiseptics. J Trauma. 2009;66:82-90

26. Pallasch TJ, Slots J. Antibiotic prophylaxis and the medically compromised patient. Periodontol 2000. 1996;10:107-38.

27. Demir A, Malkoc S, Sengun A, Koyuturk AE, Sener Y. Effects of chlorhexidine and povidone-iodine mouth rinses on the bond strength of an orthodontic composite. Angle Orthod. 2005;75:392-6.

28. Breschi L, Cammelli F, Visintini E, Mazzoni A, Vita F, Carrilho M, et al. Influence of chlorhexidine concentration on the durability of etch-and-rinse dentin bonds: a 12-month in vitro study. J Adhes Dent. 2009;11:191-8.

29. Perdigao J, Denehy GE, Swift EJ Jr. Effects of chlorhexidine on dentin surfaces and shear bond strengths. Am J Dent. 1994:7:81-4.

30. Meiers JC, Shook LW. Effect of disinfectants on the bond strength of composite to dentin. Am J Dent. 1996:9:11-4.

31. de Castro FL, de Andrade MF, Duarte Junior SL, Vaz LG, Ahid FJ. Effect of $2 \%$ chlorhexidine on microtensile bond strength of composite to dentin. J Adhes Dent. 2003:5:129-38

32. Pappas M, Burns DR, Moon PC, Coffey JP. Influence of a 3-step tooth disinfection procedure on dentin bond strength. J Prosthet Dent. 2005;93:545-50.

33. Carrilho MR, Carvalho RM, de Goes MF, di Hipolito V, Geraldeli S, Tay FR, et al. Chlorhexidine preserves dentin bond in vitro. J Dent Res. 2007:86:90-4

34. Carrilho MR, Geraldeli S, Tay F, de Goes MF, Carvalho RM, Tjäderhane L, et al. In vivo preservation of the hybrid layer by chlorhexidine. J Dent Res. 2007:86:529-33

35. Montagner AF, Sarkis-Onofre R, Pereira-Cenci T, Cenci MS. MMP inhibitors on dentin stability: a systematic review and meta-analysis. J Dent Res. 2014;93:733-43.

36. Campos EA Correr GM, Leonardi DP, Barato-Filho F, Gonzaga CC, Zielak JC Chlorhexidine diminishes the loss of bond strength over time under simulated pulpal pressure and thermo-mechanical stressing. J Dent. 2009:37:108-14.

37. Yuan Y, Shimada Y, Ichinose S, Tagami J. Qualitative analysis of adhesive interface nanoleakage using FE-SEM/EDS. Dent Mater. 2007;23:561-9.

Ready to submit your research? Choose BMC and benefit from:

- fast, convenient online submission

- thorough peer review by experienced researchers in your field

- rapid publication on acceptance

- support for research data, including large and complex data types

- gold Open Access which fosters wider collaboration and increased citations

- maximum visibility for your research: over $100 \mathrm{M}$ website views per year

At BMC, research is always in progress.

Learn more biomedcentral.com/submission 